\title{
Teachers dealing with learners' achievement - what do their emotions tell us?
}

\section{Carola Steinberg}

\begin{abstract}
Hargreaves $(1998,2004)$ has clarified the multiple ways in which teaching, including assessment, is an emotional practice. In this article I present one facet of teachers' emotions in relation to assessment, namely, their emotions towards the quality of achievement produced by their learners. The data comes from teachers who were committed to their profession, talking in focus groups about the range of emotions they experience in relation to various 'objects' (Nussbaum, 2001) within their assessment practice. The descriptive analysis of their common emotions illustrates how teachers are on an emotional rollercoaster in response to the 'object' of learners' achievement, with positive emotions in response to strong, and negative emotions in response to weak achievement. It also illustrates how teachers see themselves and their effort reflected both in strong, and in weak learner achievement. Turner's (2007, p.99-100) principle that "individuals will make attributions about the cause of their emotional experiences", with positive emotional arousal tending towards self-attributions and negative emotional arousal tending towards external attributions, makes this self-attribution of committed teachers for not only strong but also weak learner achievement a significant finding.
\end{abstract}

\section{Introduction}

My interest in researching teachers' emotions in relation to assessment was stimulated by the contradiction between the experienced reality of teachers (and teacher educators) feeling anxious, irritated and despairing about their jobs during exam times, yet when I asked, they advocated assessment as a necessary lever for individual advancement and educational quality. Why is something we experience as not conducive to our emotional well-being nevertheless staunchly supported intellectually?

I turned to the burgeoning literature on teacher emotions and found that Hargreaves $(1998,2000,2001)$ presents convincing evidence that "teaching is an emotional practice" which "activates, colours and expresses" (1998, p.838) the feelings of teachers and those with whom they work. He describes how emotions shape teachers' relationships with students, school structures, 
pedagogy, curriculum planning, parents, colleagues and educational change/ reform. Yet he barely mentions emotions about assessment. Nor do other researchers who have written about teacher emotions (e.g. Bahia, Freire, Amaral and Estrela, 2013; Bullough Jnr, 2011; James, 2011; Kelchtermans, 1996, 2005, 2011; Nias, 1996; Oplatka, 2007; Palmer, 1998; Winograd, 2003; Zembylas, 2005).

As a sub-set of teaching, assessment is also an emotional practice for teachers (Steinberg, 2008). Assessment is core to the purpose of teaching because it is the mechanism for establishing whether or not learning has taken place. At the same time, assessment is a conflicted aspect of teachers' work: the curriculum and assessment policy changes frequently, the social pressures are intense, (e.g. learners and parents expect high marks, newspapers blame teachers for low results) and the moral demand for fairness is ever-present. These often conflicting pressures inevitably arouse intense emotions in teachers.

\section{Emotions as a conceptual lens for research}

The centuries-old Western understanding of thinking as rational and emotions as irrational has been laid to rest by modern neuroscience (Damasio, 1994; Le Doux, 1999), giving rise to the insight that "it is the interaction between cognitive and emotional capacities that makes rationality and memory possible on a human scale" (Turner, 2007, p.37).

Nussbaum (2001) explores this interaction by emphasising that "emotions are about something: they have an object" (p.27) and they "direct us to an important component of our well-being and register the way things are with that important component" (p.135). Emotions are intertwined with "complex beliefs" (p.28) and "see their object as invested with value and importance" (p.30). Thus, "emotions are acknowledgements of our goals and their status" (p.135). Yet in spite of the object's importance, we cannot control it, and so "the emotion records that sense of vulnerability and imperfect control" (p.43). Archer (2000) describes how these 'objects' come from different sources: 'objects' from the natural order evoke physical feelings like pain or cold and demand our attention to physical wellbeing; 'objects' from the practical order evoke emotions like curiosity or anxiety and demand attention to performative achievement; while 'objects' from the social order evoke a whole range of 
emotions that relate to our self-worth in social interactions. These 'objects' and the resulting emotions can often be conflictual, for example, when exhaustion (from the natural order) intersects with feeling responsible for marking a pile of exams (practical order), or when the pleasure at learner engagement during lessons (practical order) co-exists with the fear that engagement may slow down curriculum coverage, resulting in a reprimand from district officials (social order). These emotional conflicts generate an "inner conversation" (p.209) to prioritise concerns and actions for decision-making. Nussbaum thus enables the understanding that the intensity of emotion is proportional to the significance of the object in our own scheme of things, while the valence (positive or negative) of the emotion indicates whether we appraise the object's impact on our well-being as supportive or threatening. Archer enables us to see how human agency is shaped by a reasoning process initiated by emotions that arise in response to physical, practical and social demands.

In addition, Turner $(2007,2010)$ provides the understanding that emotions are not only a personal but also a social force. "Emotions are embedded in social structure and culture" in a two-way process: "emotions are systematically generated under sociocultural conditions and, once aroused, they have effects on these conditions" (Turner, 2007, p.66). He develops a conceptual scheme through which he can show how "emotions generated in micro-level encounters are often the fuel for either change of, or commitment to, mesoand macrostructures and their respective cultures" even though "most of the time" personal encounters and institutional processes are constrained by the culture and structure of the level above (2010, p.171). Emotions have this power because love/loyalty and other strong positive emotions generate well-being and thus function as "symbolic media", which, like the symbolic media of money, power, health or knowledge, are distributed by institutional domains (2010, p.173) and once acquired, can be used to accumulate not only more positive emotions but also more of other symbolic media. So, for example, a teacher with a mainly positive emotional valence is more likely to inspire effort and higher marks from learners and then be promoted to HoD, thus gaining more money and power, compared to a depressed teacher. This makes positive emotions a valued resource, both intrinsically and socially. Yet, like money and knowledge, they are distributed unequally, so that the "distribution of positive and negative emotional energies among members of a population will generally correspond to the distribution of other resources such as money, power, prestige, influence and love" (2010, p.175). So, for example, teachers in a school attended by children whose parents have 
sufficient socio-economic resources will have more opportunities to gain the symbolic medium of positive emotions in response to learner achievement compared to teachers working in schools situated in poor socio-economic contexts. Turner enables us to see how personal emotions are both aroused by and become an influential factor in the operation of institutional and societal structures. Turner's sociological theory of emotions also offers two concepts particularly useful for analysing teachers' emotions towards learner achievement, namely, self-verification and attribution, which will be presented later, together with the relevant data.

Taken together, Nussbaum, Archer and Turner enable a complex understanding of the functions and effects of emotions, thus making emotions a useful lens for data analysis. Emotions provide a value judgement about 'objects' that are important to us and initiate inner conversations which motivate decision-making and action. They are also a social factor, shaped by and shaping institutional structures and cultures. Positive emotions are intrinsically desirable and function as a 'social medium' distributed by institutions such as schools and education systems. Using emotions as a research lens thus enables insight into individual as well as institutional perspectives and decision making.

\section{Research into teachers' emotions in institutional contexts}

As mentioned above, there is a growing literature into teachers' emotions, which provides valuable insights into teachers' work and identity. I don't have the space to review it here, rather, I want to draw out one key learning namely the relationship between teachers' emotions and the institutional contexts in which they work.

Hargreaves (1998) emphasises that "the emotions of teaching, their nature and form - be it "happiness" or "anxiety, frustration, anger, guilt and other negative emotions" (p.841) - are shaped by teachers" "moral purposes" (p.838) and "are therefore inextricably bound up with the basic purposes of schooling - what the purposes are, what stake teachers have (and are asked to have) in them, and whether the working conditions of teaching make them achievable or not" (p.841). Hargreaves thus centrally links teachers' emotions 
to their beliefs and ideals about the purposes of education, as well as to their institutional working conditions.

Kelchtermans (2011) strengthens this argument by explaining how teachers are positioned institutionally in a way that generates vulnerability with intense positive and negative emotions. He demonstrates how vulnerability is a "structural condition of teaching" (p.80) which has both moral and political dimensions and becomes manifest at three levels of the education system. At the level of the system, teachers are politically vulnerable in the face of policies and decisions made by education departments, especially when the designated changes affect their daily workplace context and conditions, yet the reasons and moral norms of the changes are not discussed or explained. At the level of the school, teachers are vulnerable in the micro-politics of the professional relationships in the school, especially when political conflicts arise over resources or organisational procedures that appear to be technical issues, but are actually based on different moral conceptions of what "good education" or "being a proper teacher" entails (p.76). The deepest structure that generates vulnerability in teachers is found in the classroom, namely the "limits to their professional efficacy: students' learning outcomes are only partly determined by teachers' action" (p.71). In spite of their moral ideals and their best efforts, not all learners will learn what the teacher presents and "successful outcomes remain uncertain" (p.72). This confronts teachers with "the limits of their impact" as well as "the limits of their professional knowledge and skills" (p.72), generating vulnerability.

It is this limited impact and, by implication, limited professional knowledge and skill, that is measured and made publically visible through the results of learner assessment. Low learner achievement makes teachers structurally vulnerable: at system level, it may affect promotion opportunities; at school, their reputation is at stake; personally, it questions their sense of what it means to be a 'proper teacher'. The more emphasis the education system places on assessment, the more the limits of the efficacy of teachers are in full public view. No wonder assessment results arouse intense emotions in teachers. 


\section{Research into teacher emotions in assessment}

The international research studies concerned with teachers' emotions towards assessment are small in number, yet illuminating. Some studies showed teachers grappling with the emotional complexities of their assessment practice. Stough and Emmer (1998) illustrated how teachers are reluctant to give formative feedback on tests because they struggle to manage the intensely emotional responses from students in that context. Reyna and Weiner (2001) demonstrated how teachers' emotions towards test results are interdependent with their attribution for the cause of failure: teachers are more sympathetic when failure is not the student's 'fault', and angrier when they think the student has made insufficient effort.

Other studies explored teachers' emotions towards the institutional aspects of assessment. Hargreaves (2004) theorised how accountability measures that increase the public visibility of failure might generate emotions that reinforce class differences and are difficult to acknowledge.

Empirical studies provided clear evidence that externally set, standardised assessments increase the intensity and discomfort of teachers' emotions (Smith, 1991; Hargreaves, 1994, 2003; Stecher \& Barron, 1999), while high-stakes standardised assessment can lead to teacher demoralisation, particularly in low socio-economic contexts where students have little chance of success or where the external assessments do not correspond with teachers' ideals of good teaching (Falk and Drayton, 2004). Teachers' most intense emotions were expressed towards accountability measures that assess their work directly, like school evaluations or performance appraisals, leaving them angry, ashamed and professionally weary (Jeffrey and Woods, 1996; Mahony, Menter and Hextall, 2004). Occasionally, when teachers are activated by their negative emotions, they can become determined to reveal and agitate against the excesses of accountability (Kornfeld, Grady, Marker and Ruddell, 2007). Yet generally, the intensely negative emotions and long-lasting effects evoked in teachers by accountability measures left them demoralised and "ontologically insecure" (Ball, 2003) long after the evaluation had taken place.

I did not find South African studies that dealt directly with teachers' responses to assessment and learner achievement. Yet there are studies investigating teacher stress, which found high levels of resignation, burnout, 
cynical attitudes and demoralisation (Naidoo, Botha and Bisschoff, 2013; Pienaar and van Wyk, 2006; Hayward, 2003). This gap in the South African literature increased my interest in how local teachers experienced assessment and what issues arose for them while they were doing and reflecting on it.

\section{Collecting and coding the data of this study}

The data on which this research is based came from 7 focus group interviews conducted in Johannesburg in 2008/9 with 19 experienced senior phase teachers in functional, urban, public schools, ranging from well-resourced schools serving middle class areas to resource-poor schools serving working class and squatter communities. Teachers were recruited into the study through fortuitous connections and post-graduate students who invited their colleagues. The interview asked about teachers' emotions in relation to: the value of assessment, their memories, assessment policy, learners, marking, report writing, accountability, and managing their emotions. The interview data was systematically coded using Atlas-Ti and then analysed by thematic content, so this article presents the findings of an interpretative qualitative study.

The participating teachers took their jobs seriously: they enjoyed teaching 'most of the time', they experienced teaching as 'rewarding' and 'fulfilling' because it was 'good to work and assist the community' and contribute to something that was 'essential to the future success of our country'. Yet although they 'loved working with the kids', they did not appreciate the 'insane demands of the paperwork' and they were divided on whether or not to recommend that their children become teachers. As a group, they enabled me to record the beliefs and emotions of committed teachers working within the framework of a functioning system. They did not heroically fight against all odds to change the lives of their learners and community, but they were committed to doing a good job, wanted to make a difference and invested their life energy in their profession. As Cheryl said, 'real teachers' care about what they are doing: 'I really think that there is a whole emotional investment. If you're a teacher, there's an emotional investment, if you are really a teacher'. They understood 'real' teachers as emotionally committed to making an effort so that learners can achieve. 
After much careful coding, re-coding and counting of all the utterances of teachers about assessment that contained strongly expressed emotions, what emerged were three key 'objects' (Nussbaum, 2001) within assessment that teachers were concerned with and felt strongly about: learner achievement, assessment practice and accountability demands. For the purposes of this article, I am engaging only with teachers' emotions towards the 'object' of learner achievement.

\section{Presenting the data: teachers' emotions towards learner achievement}

The single code that was numerically most prominent was emotions towards the 'object' of 'learner achievement'. In terms of their emotional focus, the teachers in this study were most concerned with the achievement of their own learners, followed by the achievement of the learners in their school and in the nation as a whole. Ideally, they wanted all learners to achieve and pass. Hargreaves (1998) argues that teachers' relationship with students is the "emotional filter" (p.842) through which they see the value and rewards of being a teacher. In response to questions about assessment, the teachers in this study illustrated how their emotional filter was substantively concerned with the growth, achievement and success of learners.

Teachers' emotions follow the quality of learner achievement

Teachers were 'quite involved emotionally' with their learners' development and assessment results. Weak learner achievement generated palpable distress: it made teachers feel 'very disappointed', 'extremely frustrated', 'horrible', 'sad', 'irritated', 'hurt' and 'sorry for learners'. Teachers took for granted that learner achievement reflected on their own performance and talked about how, when faced with the failure of their learners, they 'felt like an idiot' and wanted to 'hide away', 'went mad', 'tried to deal with burning anger', got 'frustrated' and 'depressed', all underpinned by a helplessness of 'we don't have strategies to solve that'.

When there was no learner achievement, i.e. when teachers did not manage, through their effort, to enable learning, the teacher-learner relationship could come to an end. Celiwe described it graphically: "When they fail, they end up 
absconding out of your house, because they weigh themselves as failures, as slow learners". Even if the relationship did not come to a complete end (children are, after all, legally obliged to go to school), the teachers struggled to maintain their motivation to continue teaching. Unless learners 'put their hearts into it' and performed, it became 'hard' for teachers to continue 'putting in such a lot of effort' and motivating themselves, because they felt 'demoralised', 'very upset', 'deeply disappointed', 'absolutely heartbroken' and 'very de-motivated'. When the distress over low learner achievement and the resultant self-accusation became too extreme and painful, they considered leaving the profession:

We become confused about why all the learners are failing. Where is the problem? What is it that I've not done right? So it's very bad, it's painful. You can end up saying, maybe it's because I am a failure, that is why I could not bring the subject closer or clearly to learners. Maybe that is why other people leave teaching. (Thobile)

These feelings intensified when teachers looked beyond the learners in their class to the broader picture nationally, which left them 'shocked and scared' because learners 'cannot write letters properly, they can't spell properly, they can't read documents and comprehend properly, so there are these huge gaps' and they haven't built the mental capacity either', which is 'brewing disaster' for the country. Thobile summed it up: "At the end you cry; there is no help".

The only antidote to this distress was strong learner achievement, which made teachers feel 'satisfaction', 'reaffirmed', 'worthwhile', 'most wonderful', 'rewarded', 'having their moment' and even 'having a life!'. When learners understood and 'I can see what I was teaching them', teachers felt 'proud', very happy', 'very excited', 'so good' and 'uplifted'. Learner success was the internal motivator that drove these teachers to do their work.

When the learners pass you become motivated, like, I want to do this again, and more and more. Because you want to see them passing again, at different levels every time. So you become intrinsically motivated because learners do well. (Thobile)

The quality of learner achievement generates an intense emotional rollercoaster ride for teachers

The teachers in this study talked about how they 'get upset about failures' and 'feel good when kids do unexpectedly well'; how, depending on learners' achievement, they feel 'like a failure' or like 'we've done something!'; how they feel 'enthusiastic' when learners respond well to an assessment task and 
'disappointed and de-motivated' when learners don't. The peaks of positive emotions (joy, satisfaction, excitement) when learners achieve motivated the teachers to further effort, yet alternated with sloughs of dark emotions (self-doubt, despondency, frustration) when learners did not understand or failed, which de-motivated teachers. These emotional rollercoaster rides were not under the teachers' control. Teachers were being pulled into the ups and downs by the quality of their learners' work, by their learners' emotional responses towards assessment results, and by their own empathy with learners.

This interdependence between teachers and learner achievement places teachers in a position of permanent tension. Their effort is a necessary but not a sufficient condition for good learner achievement. Learners are the ones who need to do the learning, with teachers having a strong shaping influence on, but not control over, their learners' assessment results. This makes teachers' continued motivation and effort dependent on a positive response to assessment by the learners. As teachers don't control the direction of the ride, they are hanging on to the seatbelts of their emotional rollercoaster for dear life.

The next quote illustrates how Khumbula, even when he is specifically setting out to describe the 'not gloomy' feelings about assessment, slides up and down the emotional rollercoaster.

I don't think we need to look only at the gloomy part of assessment (laughs). We should also think about the other parts that really make us happy, or sometimes uncomfortable. What makes me happy when it comes to assessment is: when I do the question, the interaction with the learners, asking them questions and the responses I get. ... Giving them feedback as well, maybe to add a little bit more on what they've given me, to extend their knowledge, I like that. That's what I enjoy very much, the interaction with them. Then what really upsets me is marking low quality work from a learner, after having spent so much time speaking to them or having activities that would really lead to better understanding and you still find some learners are just lethargic, they don't even care (laughs). Sometimes they don't even write anything. Then you wonder, why is this child not motivated? Maybe you also need to think about learners' feelings as well when it comes to certain activities. Maybe we bore them; we don't know (laughter). (KG15-K)

Khumbula sets out to speak about the aspects of assessment that make him 'happy', but the word 'uncomfortable' follows in the next breath. He 'very much enjoys' the 'interaction' and 'giving feedback that extends learners' knowledge', but gets 'really upset' by learners who are not engaged and give him 'low quality work'. Then he 'wonders' why the learners are 'lethargic' and 'not motivated', which leads him back to his sense of himself as a teacher 
and the things he is 'maybe' not doing ('considering their feelings') or unwittingly doing ('boring them'). Getting such varied responses from learners (both positive responses and lethargy) makes his emotions fluctuate wildly, leaving him concerned and insecure about the impact of his work on the learners.

The intensity of these rollercoaster emotions portrays the importance of the 'object' of learner achievement to teachers, indicating how close learner achievement is to the heart and identity of committed teachers. The intensity becomes significant in the light of the human need for self-verification. Turner (2007) clarifies that "individuals want to have their views of themselves verified" because their "sense of self is on the line during interactions" with others (p.102). The need for self-verification becomes stronger, the closer the interaction is to the core self-conception or the main sub-identity of a person (p.103). The emotional intensity with which teachers respond to learner achievement enables the insight that it is the core professional self-worth of teachers that is verified (or not) by the achievement of their learners. For committed teachers, assessment is an emotional practice that lies at the centre of their professional identity.

\section{Learner achievement generates much self-reflection in teachers}

The reflection on their professional identity was particularly prominent at times when teachers' expectations of achievement were not met. Faced with learner non-achievement, they felt 'embarrassed', 'bad', 'confused', 'inadequate', 'apprehensive', 'hurt', 'pain', 'self-blaming', 'self-questioning', 'unsure', 'something wrong'. Low learner achievement made them reflect on themselves and their work: wondering why their 'best' efforts were 'not enough', whether they taught well enough, what they 'did wrong', what could have been done differently, what they could 'adjust' in the future. At times when learner non-achievement was too frequent or too severe, they even made a judgement of 'total failure' about their entire career. Hlubi spoke for all when he said:

I feel embarrassed and bad if my learners are not performing the way I wanted them to perform. Because the main aim of teaching them is to ensure they are well developed, they are well educated. But if they do badly in my assessment, I get confused, to say, what went wrong? Or where did it go wrong? Then I restart to think again and see what I can adjust, so that they can be able to get some little bit of achievement. 
Teachers' self-reflection in the mirror of learner achievement was grounded in the assumption that a teacher is a person who is responsible for children to learn something. Regardless of the socio-economic environment of their schools, the teachers reflected on and judged themselves by how well they had 'charged' their learners:

I need to take responsibility for those learners. Even if it's a case where they are never going to get A's, but they're currently getting E's and I should get them to C's. It should be like that, there's no doubt in my mind. (Cheryl, in a school with middle class children)

I think assessment is very important. You are going to assess yourself as the teacher, how much did the learner learn from you? (Mathoto, in a school with working class children)

'Real' teachers commit to responsibility for learner achievement Turner (2007) argues that in their need to understand why and how things happen, "individuals are constantly making causal attributions as to the sources of various outcomes" (p.97). Linking causal attribution to emotions, he presents a principle for the direction that the attributions will take, namely that "positive emotional arousal reveals a proximal bias with individuals making self-attributions" (p.99) while "negative emotional arousal evidences a distal bias, with individuals making external attributions" (p.100). This means there is a general tendency for the positive emotions aroused by success to lead people to attributing the cause of success to themselves (thus giving themselves a double dose of pleasurable emotions), while the negative emotions aroused by failure leads people to attributing the cause of failure to others (thus avoiding the second dose of negative emotions).

As I coded and analysed all the causal attributions for learner achievement made during the interviews, it emerged that the teachers were making self-attributions not only for the success, but also for the failure of their learners.

Table 1: Causal attributions subdivided into types of learner achievement

\begin{tabular}{|l|c|c|c|c|}
\hline $\begin{array}{l}\text { Teachers' causal attribution } \\
\text { for learner achievement to: }\end{array}$ & Learners & Self & System & Total \\
\hline High achievement & 1 & 2 & 0 & 3 \\
\hline Low achievement & 21 & 21 & 28 & 70 \\
\hline Achievement in general & 15 & 20 & 7 & 42 \\
\hline Total & 37 & 43 & 35 & 115 \\
\hline
\end{tabular}


Teachers were primarily concerned with attributing causes for the low achievement of learners (70), they often attributed causes to learner achievement in general regardless of its outcome (42), yet they seldom made an attribution for high learner achievement (3). In terms of self-attributions, they took clear responsibility for the level of learners' achievement in general (20) and in no way shirked their responsibility for low achievement (21). Teachers from all the schools made self-attributions for low learner achievement and there was no discernible pattern across socio-economic levels. Making a majority of self-attributions (43) is appropriate, as it means the teachers were taking responsibility for the core of their job. Yet they balked at taking sole responsibility for low learner achievement: they attributed blame for failure to both learners (21) and the system (28). Issues included in the attributions to the system were education policy, administrative assessment demands placed on them by the department which interfered with teaching, learners' language diversity, class sizes, colleagues lower in the system, parents, and generally overwhelming low socioeconomic conditions.

This pattern of attributions means that the teachers in this study were not following the general human pattern of making self-directed attributions for positive results and other-directed attributions for negative results, but, with regard to learner achievement, were making causal self-attributions not only for success but also for failure, thus accepting the double dose of negative emotions as their due.

\section{Discussion: Learner achievement lies at the heart of teachers' professional identity}

Like all human beings, teachers aspire to having more of the "symbolic medium" (Turner, 2010, p.173) of positive emotions, both for its intrinsic and its exchange value. Teachers with more positive emotions are more likely to have positive interactions with learners and colleagues, increasing their emotional energy in the process and becoming more likely to teach in ways that reward them with the success of high learner achievement, which in turn continues the positive cycle. In contrast, when teachers experience negative emotions because of learners' low achievement, they lose emotional energy, have less emotional symbolic media to exchange and a negative cycle ensues. When this cyclical process is linked with causal attribution, the result is intensification. When teachers receive the positive emotions and energy of 
their learners' success and at the same time make a self-attribution for that success, they feel doubly good. In the space of this positive emotional intensification, it becomes easy to make additional external attributions to learners for their effort, to colleagues and parents for their support and even to the education department for its guidance. In fact, these positive external attributions entrain others and generate more positive emotions to go around. But when teachers are faced with the negative emotions and loss of energy coming from their learners' failure, the nature and direction of their attributions really matter. If teachers make a causal self-attribution for low achievement, then they feel doubly bad - not only do they have to deal with their already felt negative emotional response to failure; they also have to deal with the self-recriminations about having caused that failure through their own incompetence or lack of effort. If they attribute the cause of low achievement to an external source, then they still feel bad about the failure, but at least they don't have to feel guilt and shame about themselves as well. It also matters towards whom the external attribution is directed - if it is directed towards learners, with whom teachers are in daily contact, the negative attribution can cause their relationship to sour, generating even more negative emotions and making the teaching an unpleasant experience. To safeguard the children from becoming the 'objects' of their negative emotions, the "inner dialogue" (Archer, 2000) of teachers may make external attributions directed towards the 'system' - department officials or parents who are seldom seen, or, even better, policy documents or unknown policy makers who cannot fight back.

In this light of this understanding, it is a pleasant surprise that the committed teachers in this study went against the general trend of attributions as predicted by Turner's principle. Even though they made some external attributions, they did not refuse to accept the double dose of negative feeling that arises from both failure and responsibility for that failure. They remained committed to their "moral purpose" (Hargreaves, 1998) of being responsible for the quality of learner achievement. They worked on the assumption that because assessment functions as a summary of what has been taught, it becomes a comment on the effectiveness of teaching, with the results reflecting on the teacher nearly as much as they do on the student. They were thus living in a "structural condition" of "vulnerability" (Kelchtermans, 2011, p.80): the more they did what is correct for their professional identity, which is to understand their role as someone who is responsible for generating the achievement of others, the more they ended up facing the "limits of their professional efficacy" (p.71) and taking responsibility for learner failure, 
which gave them a double dose of negative emotion. Their morally correct position led them into an emotionally uncomfortable place. This resonates with Hargreaves' finding that teachers feel "very insecure as a profession" because of their guilt and fear of "not measuring up" (1994, p.150).

\section{Conclusion}

Turner's (2010) claim that positive emotions function as a symbolic medium and resource that every person strives to have more of, makes visible two important implications of these findings.

The first implication is professional. As seen through the lens of their emotions, attaining high learner achievement is an intrinsic self-interest for every teacher. Too much learner failure generates negative emotions which de-energise and de-motivate teachers. If teachers want to gain access to the symbolic medium of positive emotions, i.e. to have more joy/selfgratification and less disappointment/self-doubt in the course of their work, it means that, (if they want to remain teachers and not move out into management or administrative positions), they structurally have no choice but to care about, take responsibility for, work hard and make the effort to enable good learner achievement.

The second implication is institutional. Teachers can only remain motivated to do their job to the best of their ability for as long as the highs and lows of the emotional rollercoaster balance each other out, so that the negative emotions of failure are balanced by the positive emotions of success. Teachers cannot achieve this balance alone - they are working within an institutional and societal system that shapes their working conditions. Sixty per cent to $75 \%$ of schools in our country are underperforming (Shalem and Hoadley, 2009; Hoadley, 2013), primarily for reasons arising from socio-economic factors. When failure is endemic for socio-economic reasons, there will be many occasions when the few emotional highs of learner success cannot carry teachers past the long duration of failure lows. This has implications for the emotional health of South African teachers: an overdose of the negative emotions of failure may generate instability in teachers' self-attribution for learner achievement and weaken their commitment to the effort involved in enabling learner achievement. At those times, teachers would benefit from less public blame and more institutional support (be it emotional, educative or administrative) to lift them into a more capable and hopeful feeling. Using 
Turner's language, it is important for societal attitudes and education department regulations to increase teachers' share of the symbolic medium of positive emotions.

\section{References}

Archer, M.J. 2000. Being human, the problem of agency. Cambridge: Cambridge University Press.

Bahia, S., Freire, I., Amaral, A., Estrela M.T. 2013. The emotional dimension of teaching in a group of Portuguese teachers. Teachers and Teaching: Theory and Practice, 19(3): pp.275-292.

Ball, S.J. 2003. The teacher's soul and the terrors of performativity. Journal of Education Policy, 18(2): pp.215-228.

Bullough, R.V. 2011. Hope, happiness, teaching and learning. In Day C. and Lee, J.C. (Eds). New understandings of teachers' work: emotions and educational change. Springer. Ch. 2: pp.15-30.

Damasio, A. 2006. Descartes' error: emotion, reason, and the human brain (Revised Edition with a New Preface, republished from 1994). London: Vintage.

Department of Basic Education. 2012. Curriculum and Assessment Policy Statements (CAPS). Pretoria, South Africa.

Falk, J. and Drayton, B. 2004. State testing and inquiry-based science: are they complementary or competing reforms. Journal of Educational Change, 5: pp.345-387.

Hargreaves, A. 1994. Changing teachers, changing times. London: Cassell.

Hargreaves, A. 1998. The emotional practice of teaching. Teaching and Teacher Education, 14(8): pp.835-854. 
Hargreaves, A. 2000. Mixed emotions: teachers' perceptions of their interactions with students. Teaching and Teacher Education, 16: pp.811-826.

Hargreaves, A. 2001. Emotional geographies of teaching. Teachers' College Record, 103(6): pp.1056-1080.

Hargreaves, A. 2003. Teaching in the knowledge society, education in the age of insecurity. Philadelphia: Open University Press.

Hargreaves, A. 2004. Distinction and disgust: the emotional politics of school failure. International Journal of Leadership in Education, 7(1): pp.27-41.

Hoadley, U. 2013. Building strong foundations: improving the quality of early education. In Berry, L., Biersteker, L., Dawes, A., Lake, L. and Smith, C. (Eds). South African Child Gauge 2013. Cape Town:

Children's Institute, University of Cape Town.

Hayward, R. 2003. A survey of morale among NAPTOSA members. Edu Source Data News, 41: pp.1-7.

James, C. 2011. The importance of affective containment for teacher effectiveness and successful educational change. In Day, C. and Lee, J.C. (Eds). New understandings of teachers' work: emotions and educational change. Springer. Ch. 8: pp.119-134.

Jeffrey, B. and Woods, P. 1996. Feeling deprofessionalised: the social construction of emotions during an OFSTED inspection. Cambridge Journal of Education, 26(3): pp.325-344.

Kelchtermans, G. 1996. Teacher vulnerability: understanding its moral and political roots. Cambridge Journal of Education, 26(3): pp.307-325.

Kelchtermans, G. 2005. Teachers' emotions in educational reforms: selfunderstanding, vulnerable commitment and micro-political literacy. Teaching and Teacher Education, 21(8): pp.995-1006. 
Kelchtermans, G. 2011. Vulnerability in teaching: the moral and political roots of a structural condition. In Day, C. and Lee, J.C. (Eds). New understandings of teachers' work: emotions and educational change. Springer. Ch. 5: pp.65-82.

Kornfeld, J., Grady, K., Marker, P.M. and Ruddell, M.R. (n.d.). Caught in the current: a self-study of state-mandated compliance in a teacher education programme. Teachers College Record, 109(8): pp.1902-1930.

LeDoux, J. 1999. The emotional brain: the mysterious underpinnings of emotional life. London: Phoenix.

Mahony, P., Menter, I. and Hextall, I. 2004. The emotional impact of performance-related pay on teachers in England. British Educational Research Journal, 30(3): pp.435-456.

Naidoo, K., Botha J.C. and Bisschoff, C.A. 2013. Causes of stress in public schools and its impact on work performance of educators. Journal of Social Sciences, 34(2): pp.177-190

Nias, J. 1996. Thinking about feeling: the emotions in teaching. Cambridge Journal of Education, 26(3): pp.293-306.

Nussbaum, M.C. 2001. Upheavals of thought: the intelligence of emotions. Cambridge: Cambridge University Press.

Oplatka, I. 2007. Managing emotions in teaching: towards an understanding of emotion displays and caring as non-prescribed elements. Teachers College Record, 109(6): pp.1374-1400.

Palmer, P.J. 1998. The courage to teach: exploring the inner landscape of a teacher's life. San Francisco: Jossey-Bass.

Pienaar, J. and Van Wyk, D. 2006. Teacher burnout: construct equivalence and the role of union membership. South African Journal of Education, 26(4): pp.541-551. 
Reyna, C. and Weiner, B. 2001. Justice and utility in the classroom: an attributional analysis of the goals of teachers' punishment and intervention strategies. Journal of Educational Psychology, 92(2): pp.309-319.

Shalem, Y. and Hoadley, U. 2009. The dual economy of schooling and teacher morale in South Africa. International Studies in Sociology of Education, 19(2): pp.110-134.

Smith, M.L. 1991. Put to the test: the effects of external testing on teachers. Educational Researcher, 20(5): pp.8-11.

Stecher, B.M. and Barron, S.I. 1999. Quadrennial milepost: accountability testing in Kentucky. USA: National Centre for Research on Evaluation, Standards and Student Testing (CRESST), RAND Education.

Steinberg, C. 2008. Assessment as an "emotional practice". English Teaching: Practice and Critique, 7(3): pp.42-64.

Steinberg, C. 2013. Teachers' emotions towards assessment: what can be learned from taking the emotions seriously? Unpublished $\mathrm{PhD}$ Thesis, University of the Witwatersrand.

Stough, L. and Emmer, E. 1998. Teachers' emotions and test feedback. International Journal of Qualitative Studies in Education, 11(2): pp.341-361.

Turner, J.H. 2007. Human emotions: a sociological theory. New York: Routledge.

Turner, J.H. 2010. The stratification of emotions: some preliminary generalizations. Sociological Inquiry, 80(2): pp.168-199.

Winograd, K. 2003. The functions of teacher emotions: the good, the bad and the ugly. Teachers College Record, 105(9): pp.1641-1673.

Zembylas, M. 2005. Teaching with emotion: a postmodern enactment. Connecticut: Information Age Publishing. 
Carola Steinberg

School of Education

University of the Watersrand

carola.steinberg@wits.ac.za 